\title{
Viral-mediated overexpression of the Myelin Transcription Factor 1 (MyT1) in the dentate gyrus attenuates anxiety- and ethanol-related behaviors in rats
}

\author{
Amine Bahi ${ }^{1}$ - Jean-Luc Dreyer ${ }^{2}$
}

\begin{abstract}
Rationale Myelin Transcription Factor 1 (MyT1), a member of the Zinc Finger gene family, plays a fundamental role in the nervous system. Recent research has suggested that this transcription factor is associated with the pathophysiology of psychiatric disorders including addiction, schizophrenia, and depression. However, the role of MyT1 in anxiety- and ethanolrelated behaviors is still unknown.

Objectives We evaluated the effects of lentiviral-mediated overexpression of MyT1 in the dentate gyrus (DG) on anxiety- and ethanol-related behaviors in rats.

Methods We used the elevated plus maze (EPM) and the open field (OF) tests to assess anxiety-like behavior and a twobottle choice procedure to measure the effects of MyT1 on ethanol intake and preference.

Results MyT1 overexpression produced anxiolytic-like effects in the EPM test and decreased the number of fecal boli in the OF test, without affecting locomotor activity in both behavioral tests. Next, we demonstrated that ethanol intake and preference were decreased in the MyT1-overexpressing rats with no effect on saccharin and quinine, used to assess taste discrimination, and no effect on ethanol clearance suggesting specific alterations in the rewarding effects of ethanol.
\end{abstract}

Amine Bahi

amine.bahi@gmail.com

Department of Anatomy, Tawam Medical Campus, United Arab Emirates University, Al Ain, UAE

2 Division of Biochemistry, Department of Medicine, University of Fribourg, 1700 Fribourg, Switzerland
Most importantly, ectopic MyT1 overexpression increased both MyT1 and BDNF mRNA levels in the DG. Using Pearson's correlation, results showed a strong negative relationship between MyT1 mRNA and anxiety parameters and ethanol consumption and a positive correlation between MyT1 and BDNF mRNAs.

Conclusion Taken together, MyT1 along with being a key component in anxiety may be a suitable candidate in the search of the molecular underpinnings of alcoholism.

Keywords Anxiety · BDNF · Elevated plus maze · Ethanol . MyT1 · Open field · Quinine · Saccharin · Two-bottle choice · Viral vectors

$\begin{array}{ll}\text { Abbreviations } \\ \text { BDNF } & \text { Brain-derived neutrophic factor } \\ \text { BEC } & \text { Blood ethanol concentration } \\ \text { DG } & \text { Dentate gyrus } \\ \text { EPM } & \text { Elevated plus maze } \\ \text { LV } & \text { Lentiviral vectors } \\ \text { MyT1 } & \text { Myelin Transcription Factor 1 } \\ \text { NZF-2b } & \text { Neural Zinc Finger 2b } \\ \text { OF } & \text { Open field }\end{array}$

\section{Introduction}

Anxiety is one of the most prevalent psychiatric comorbidities of alcohol use disorders. In fact, in the 1997 National Comorbidity Survey, where 5877 respondents were asked about the history of five psychiatric disorders, in their parents, including generalized anxiety disorder and alcohol abuse/dependence, results have shown significant familial aggregation for both disorders (Kendler et al. 1997). Also, the national 
epidemiological surveys reported that approximately $11.08 \%$ prevalence of anxiety disorders (representing 23.0 million US adults) and almost 9\% (17.6 million adult Americans) had an alcohol use disorder (Grant et al. 2004). Interestingly, among individuals with anxiety disorders who sought treatment, about $16 \%$ had a current substance use disorder that was more likely to be an alcohol than a drug use disorder (Grant et al. 2004). More recently, it has been reported that the prevalence of anxiety disorder was higher in females compared with males (42.2\% versus $27.4 \%$ ) and that increased predisposition to alcohol intake in negative emotional situations was associated with comorbid anxiety disorder (Karpyak et al. 2016), suggesting that treatment for anxiety should include individuals with alcohol use disorders to maximize positive treatment outcomes. As such, identifying the molecular mechanisms common to anxiety and alcohol abuse may prove crucial to successfully treating alcohol dependence. Previous investigations aimed at identifying the neuroadaptations pertinent to this comorbidity have revealed a potential role for brain zinc finger protein dysregulations in both anxiety and alcohol use disorders (Wang et al. 2016).

Zinc finger $(\mathrm{ZF})$ proteins are among the most abundant proteins in eukaryotic cells where they comprise approximately $3 \%$ to $5 \%$ of the human genome (Laity et al. 2001). So far, more than 14 different classes of ZF proteins have been identified, all of which coordinate zinc ions in a tetrahedral geometry (Matthews and Sunde 2002). These different classes share a variety of functions within the cell, in particular their ability to mediate the interaction of proteins with DNA, as over half of all human transcription factors contain ZF domains (Eom et al. 2016). The most well-studied DNA-binding ZFs are the "classical" ZF protein family containing classical $\mathrm{Cys}_{2} \mathrm{His}_{2}$ domains which ligate zinc via pairs of cysteine and histidine residues (Eom et al. 2016). The "nonclassical" ZF proteins are less well studied, and these proteins adopt a large range of secondary structures upon zinc coordination (Matthews and Sunde 2002). The Myelin Transcription Factor (MyT) family belongs to the nonclassical ZF proteins which are highly involved in the development of the central nervous system (CNS) (Nielsen et al. 2004). Based on their sequences and structures, three members have been identified: Neural Zinc Finger Factor 1 (NZF-1 or MyTL-like or png-1), Myelin Transcription Factor 1 (MyT1 or NZF-2), and Suppression of Tumorigenicity 18 (ST18 or NZF-3) (Jiang et al. 1996). The MyT1 contains seven ZF modules (Gamsjaeger et al. 2013), which was identified as the transcription factor responsible for binding to the protein (PLP) promoter (Nielsen et al. 2002). Because MyT1 is involved in several neurodevelopment pathways, increasing lines of evidence support an important role of MyT1 in psychiatric disorders such as schizophrenia and major depressive disorder (MDD) (Fernandez-Enright et al. 2014; Li et al. 2012; Wang et al. 2010). Given the fact that most antidepressant treatments are believed to target mainly the dentate gyrus (DG) of the hippocampus through activation of the neurotrophic factor brain-derived neutrophic factor (BDNF) (Kitahara et al. 2016), a major target of Myt1, we hypothesize that alterations of BDNF expression through manipulation of MyT1 expression, using viral vectors in the DG, will affect both anxiety- and ethanol-related behaviors.

Both human and animal studies support the fact that dysfunctions of the DG are associated to the pathophysiology of anxiety and alcohol use. In fact, Gould et al. have shown that anxiety has been associated with reduced proliferation in the DG of adult rodents (Gould et al. 2000). Also, results have demonstrated that chronic antidepressant treatment significantly increased neuronal proliferation in the adult DG (Malberg et al. 2000), and anxiety induced by stress and depression-like conditions in animal models are associated with reduced DG proliferation (Czeh et al. 2001). Furthermore, multiple binge ethanol exposure substantially reduced neurogenesis in the DG of adolescent mice (Lacaille et al. 2015). Also, moderate alcohol consumption reduced the number of cells produced in the DG by nearly $40 \%$ (Anderson et al. 2012). Taken together, there might be a link between the reduced neurogenesis, anxiety, and ethanol consumption if one gives credit to the hypothesis that anxiety is associated with reduced neurogenesis in the DG (Earnheart et al. 2007; LealGalicia et al. 2007; Trejo et al. 2008). We have previously explored the roles of MyT1 in the development of cocaineinduced locomotor stimulation and self-administration (Chandrasekar and Dreyer 2010a, 2010b) and found that lentiviral-mediated modulation of MyT1 alters cocainerelated behaviors in rats. There is evidence from animal studies that common molecular mechanisms contribute to both addiction to psychostimulant, anxiety disorders, and alcoholism (Kampman et al. 2002). Therefore, we hypothesized that the identification of MyT1 as candidate gene for schizophrenia, MDD, and cocaine self-administration justifies further mechanistic studies on its role in anxiety-like behavior and voluntary ethanol intake and preference in rodents. To further test this hypothesis and as an extension of our previous observations, we assessed in the present study whether MyT1 overexpression in the DG of the hippocampus plays a role in anxiety- and alcohol-related behaviors. A first set of experiments was conducted to assess the hypothesis that in vivo genetic overexpression of MyT1 in the DG can alter anxiety in the elevated plus maze (EPM) and OF tests. Second, we investigated the effects of MyT1 overexpression on voluntary ethanol consumption and preference in rats using a two-bottle choice continuous access model. The effects of MyT1 overexpression on saccharin and quinine solutions consumption were also evaluated to determine whether these lentiviral vectors would produce nonselective impairment of the drinking of liquids. 


\section{Materials and methods}

\section{Animals}

Adult male Wistar rats, obtained from the central breeding facility, were housed in groups of five per cage and were given 7 days for acclimation to a 12:12-h light/dark cycle (light on between 6:00 am and 6:00 pm). The animal facility at our college typically used a woodchip bedding, which when touched feels somewhat prickly, even though the wood pieces are small. Woodchip bedding was produced locally and autoclaved before use. The rats had free access to tap water and standard rodent chow diet obtained from the National Feed and Flour Production and Marketing Company LLC (Abu Dhabi, UAE). The institutional Animal Research and Ethics Committee approved the study (Approval No. A1712).

\section{Drugs}

For the two-bottle choice drinking procedure, the ethanol solution $(5 \%, v / v)$ was prepared from absolute ethyl alcohol (Panreac Quimica SAU, Barcelona, Spain) and diluted using tap water. For taste sensitivity, saccharin sodium salt dihydrate $(0.04$ and $0.08 \%, w / v)$ and quinine hemisulfate (15 and $30 \mu \mathrm{M}, w / v$ ) were purchased from Sigma-Aldrich (St. Louis, MO, USA) and were dissolved in tap water. For the blood ethanol concentration (BEC) experiments, ethanol prepared from $20 \% v / v$ dissolved in physiological saline $0.9 \%$ sodium chloride and sterile water and has been used for intraperitoneal (i.p.) injections at a dose of $3 \mathrm{~g} / \mathrm{kg}$.

\section{Construction of the MyT1 vectors and virus production}

Plasmid construction was described in previously published work from our laboratory (Chandrasekar and Dreyer 2010a, 2010b). The empty pTK431 was used as a negative control (Mock). For lentiviral production, a triple transfection protocol was used as described previously (Bahi et al. 2008). Briefly, the pTK431-transfer plasmids together with the packaging $\mathrm{p} \triangle \mathrm{NRF}$ and the envelope pMDG-VSV-G plasmids were co-transfected into HEK293T cells. The viral particles were purified and concentrated using ultracentrifugation.

\section{Stereotaxic surgery and viral injection}

Rats were anesthetized with a cocktail of ketamine $(100 \mathrm{mg} / \mathrm{kg}$, i.p.) and xylazine $(10 \mathrm{mg} / \mathrm{kg}$, i.p.) and placed in a stereotaxic frame apparatus. The deep anesthesia was confirmed by the absence of a pedal withdrawal reflex to a toe pinch. Using ear bars, the head was fixed in a Kopf stereotaxic frame (Tujunga, CA, USA), a midline incision was made, and the bregma was measured from the skull surface. Three

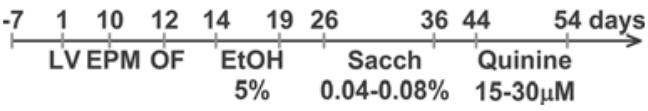

Fig. 1 Summary of the experimental procedure. $L V$ lentiviral injection, $E P M$ elevated plus maze, $O F$ open field, $E t O H$ ethanol, Sacch saccharin

injections were made into different anteroposterior sites to target the DG of the hippocampus as follows: -3.8 anteroposterior (AP) to the bregma, \pm 0.6 to 1.6 lateral, and -3.1 to -4.0 dorsoventral (DV) from dura; $-4.3 \mathrm{AP}, \pm 1.3$ to 2.3 lateral, and -3.2 to $-4.0 \mathrm{DV}$; and $-4.8 \mathrm{AP}, \pm 1.8$ to 2.8 lateral, and -3.3 to $-4.1 \mathrm{DV}$ (Bahi 2016; Paxinos and Watson 1998) (Suppl. Fig. 1). Microinjections were made using a 26G Hamilton syringe. Each injection was made over a period of $5 \mathrm{~min}(0.1 \mu \mathrm{l} / \mathrm{min}, 0.5 \mu \mathrm{l}$ total volume $)$, and the needle was left in place for an additional $10 \mathrm{~min}$ before removal to permit time for the vector to diffuse from the needle tip and minimize upward flow of viral solution. The Hamilton microsyringe was rinsed with saline before being refilled for the next injection. The incision was closed, and animals were given postoperative analgesia buprenorphine $(0.05 \mathrm{mg} / \mathrm{kg}$ in $3 \mathrm{ml}$ prewarmed isotonic saline subcutaneously). Rats were singly housed with access to two bottles of water and left to recover 10 days before behavioral experiments started. The general design of the study is depicted in Fig. 1.

\section{Anxiety- and ethanol-related behavior tests}

All anxiety-like behavior tests were conducted between 9:00 AM and 3:00 PM, and animals were habituated to the room for $1 \mathrm{~h}$ before starting the respective test. The general design of the study is depicted in Fig. 1.

Elevated plus maze test As described previously, we used a standard EPM assay to assess anxiety-like behavior (Bahi 2016; Bahi et al. 2016). In brief, the apparatus consisted of two open arms $(\mathrm{OA})\left(50 \times 10 \mathrm{~cm}^{2}\right)$ and two enclosed arms (CA) $\left(50 \times 10 \times 40 \mathrm{~cm}^{3}\right)$, which were connected by a central platform $\left(10 \times 10 \mathrm{~cm}^{2}\right)$. Each rat was placed in the central platform facing an open arm and could freely explore the maze for $5 \mathrm{~min}$. The number of entries and the time spent in each arm of the maze were hand scored and precautions were taken to keep the experimenter blind to condition. After each session, fecal boli were removed, and the maze was cleaned with a $70 \%$ pure ethanol solution to remove odor trails.

Open field (OF) test Spontaneous and exploratory locomotor activity and anxiety were tested in an OF test as reported in our previous studies (Bahi 2016; Bahi et al. 2016). In brief. Each rat was placed in the corner of the open field arena $\left(100 \times 100 \times 20 \mathrm{~cm}^{3}\right)$ and allowed to explore for $15 \mathrm{~min}$. The time spent in the center of the arena, the number of line crossings, and the number of fecal boli were hand scored and precautions were taken to keep the experimenter blind to 
condition. The tendency of a rat to enter this center zone was used as an indication of anxiolytic-like phenotype. The anxiogenic-like phenotype was supported by increased number of fecal boli left in the arena (Amorim et al. 2014; Aubrecht et al. 2014; Ghisleni et al. 2008). After each session, fecal boli were counted and removed, and the open field arena was cleaned with a $70 \%$ pure ethanol solution to remove odor trails.

\section{Continuous access to alcohol in two-bottle choice drinking paradigm}

The typical two-bottle choice drinking paradigm procedure described previously (Bahi 2013) was used with minor modifications. In brief, the rats were weighed and given access to two-bottles, one containing tap water and the other containing $5 \%$ ethanol. Throughout the experiment, evaporation/spillage estimates were calculated daily from two bottles placed in an empty cage. The bottles were weighed every day and the quantity of ethanol consumed ( $\mathrm{g} / \mathrm{kg}$ body weight/24 h) was calculated for each rat. Fluid intakes in grams were converted to milliliters with the assumption that for water $1 \mathrm{~mL}=1 \mathrm{~g}$, and for ethanol $1 \mathrm{~mL}=0.0395 \mathrm{~g}$. The ethanol preference was calculated as volume of ethanol consumed per total volume of water plus ethanol consumed. Total fluid intake was calculated and expressed as volume of water plus ethanol consumed per kilogram of body weight per day ( $\mathrm{ml} / \mathrm{kg} / \mathrm{day})$. The values for ethanol consumption, preference and the total fluid intake were averaged across the 5-days period. The general design of the study is depicted in Fig. 1.

\section{Continuous access to tastant in two-bottle choice drinking paradigm}

The same rats were also tested for saccharin and quinine consumption and preference to assess whether the decreased ethanol consumption and preference observed in MyT1overexpressing rats may be due to the pharmacological effects of ethanol. One bottle always contained water, and the other contained the tastant solution. In brief, 7 days after completion of the ethanol consumption test, a saccharin drinking test was initiated, where the rats were given the choice between increasing concentrations of saccharin $(0.04$ and $0.08 \%)$ and tap water. After completion of the saccharin drinking test and a respective 7-day washout period, rats were given access to increasing concentrations of quinine $(15$ and $30 \mu \mathrm{M})$ and tap water. For both tastants, each concentration was offered for 5 days with the low concentration being presented first, followed by the higher concentration and with bottle position changed daily to control for side preference. Fluid intake (water, saccharin, or quinine) was measured every $24 \mathrm{~h}$, and body weights were recorded every 5 days throughout the whole study. As for ethanol, tastant intakes and total fluid intakes were corrected for body weight of the subject. The general design of the study is depicted in Fig. 1.

\section{Blood ethanol concentration}

To estimate whether MyT1 overexpression altered ethanol pharmacokinetics, the four experimental groups of rats were given i.p. injections of $3 \mathrm{~g} / \mathrm{kg}$ (i.p.; $20 \% \mathrm{v} / \mathrm{v}$ in isotonic saline) doses of ethanol, and blood samples were collected 1, 3 and $6 \mathrm{~h}$ later to estimate BECs. Approximately $50 \mu \mathrm{L}$ of blood samples were withdrawn from the tail vein and collected immediately into tubes containing ethylenediaminetetraacetic acid (EDTA) for separation of plasma. The tubes were centrifuged and the plasma was separated and stored at $-20{ }^{\circ} \mathrm{C}$. BECs were measured in milligrams per deciliter (BioVision Research Products, CA, USA) as described previously (Bahi 2013).

\section{RT-PCR and MyT1 quantification}

Rats were decapitated at the end of the behavioral tests, and the DG were immediately dissected out as we described previously (Bahi 2016). Briefly, the brain was removed from the skull and placed into RNase-free ice-cold PBS. The brain was cut along the longitudinal fissure, and the regions posterior to lambda were removed. The cerebral hemisphere was placed medial side up and the diencephalon was carefully removed exposing the dentate gyrus in the medial side of the hippocampus. A stainless needle tip (12 gauge) was then inserted into each side of the DG and slid superficially along the septotemporal axis of hippocampus to isolate the DG. Total RNA was extracted by the TRIzol and precipitated with isopropanol. Total RNA was then quantified and used for cDNA preparation using a standard SuperScript III reverse transcriptase procedure. RNA expression was analyzed using an Applied Biosystems ${ }^{\circledR} 7500$ RT-PCR Instrument. SyberGreen, purchased from Applied Biosystems, was used to quantify MyT1 and BDNF transcripts with temperature cycling parameters consisting of initial denaturation at $95{ }^{\circ} \mathrm{C}$ for 4 min followed by 40 cycles of denaturation at $94{ }^{\circ} \mathrm{C}$ for $30 \mathrm{~s}$, annealing, and extension at $64{ }^{\circ} \mathrm{C}$ for $45 \mathrm{~s}$. PCR for the control gene, cyclophilin, was run with the same cycling parameters. Template $(2 \mu \mathrm{l})$ was amplified by PCR in $20 \mu \mathrm{l}$ total reaction volume containing $0.5 \mu \mathrm{mol}$ of each specific PCR primer as described in our previous studies (Bahi et al. 2008; Chandrasekar and Dreyer 2010a, 2010b). The following primers sets were used for amplification: MyT1: 5'-GCA GAC CTC AGT TGT CCT ACC-3' and 5'-CTT GGA TAC CAG GTG CTC AG-3'; BDNF: 5'-GGT TCG AGA GGT CTG ACG AC-3' and 5'-CAA AGG CAC TTG ACT GCT GA-3'; and cyclophilin: 5'-GTG AGA AGG GCT TTG GCT AC-3' and 5'-TTC TCG TCA GGA AAG CGG-3'. 


\section{Statistical analyses}

For statistical comparisons, the software package IBM SPSS Statistics 16.0 was used. Data were expressed as means \pm SEM. The data representing the effects of viral infection "Mock vs. MyT1" on anxiety-like behaviors, ethanol consumption, and preference and mRNA quantification were analyzed using a one-way analysis of variance (ANOVA) with "virus" as the between-subject factors. The data representing the effects of viral infection on tastant consumption and BECs were analyzed using a one-way ANOVA with repeated measures with "concentration" and "time" as the within-subject factors, respectively, and "virus" as the between-subject factors. The acceptable level of significance was $5 \%$ for each analysis. Simple linear regression (Pearson's) analysis was performed to examine the correlation between MyT1 and BDNF mRNA levels and measures of anxiety-like behaviors and ethanol consumption and preference. The relationship is expressed as the correlation coefficient $(r)$.

\section{Results}

\section{Anxiety-like behavior}

The elevated plus maze (EPM) This test was performed 10 days after the stereotaxic injections to investigate the effects of MyT1 overexpression on anxiety-like behaviors. Analysis of the percentage of time spent into the open arms (OA) of the maze using one-way ANOVA revealed that, compared to Mock-injected rats, MyT1-injected rats spent more time into the OA $\left(F_{(1,16)}=14.452, p=0.002\right.$; Fig. 2a). Similarly, MyT1 overexpression increased the number $\left(F_{(1,16)}=32.327\right.$, $p<0.0001$; Fig. 2b) and the percentage of entries into the OA of the $\operatorname{EPM}\left(F_{(1,16)}=12.113, p=0.003\right.$; Fig. $\left.2 \mathrm{c}\right)$. Finally, there were no significant differences across the groups in the number of entries into the closed arms $(\mathrm{CA})\left(F_{(1}\right.$, 16) $=0.199, p=0.661$; Fig. 2d), indicating that locomotor activity was similar across the two experimental groups.

The open field This test was conducted to assess anxiety-like behavior and spontaneous explorative locomotor activity. By analyzing the time spent in the center of the arena, we observed no significant differences between MyT1- and Mockinjected rats $\left(F_{(1,16)}=2.148, p=0.162\right.$; Fig. 2e). However, MyT1 overexpression decreased the number of fecal boli produced during the OF test, an anxiolytic-like response (Aubrecht et al. 2014; $F_{(1,16)}=4.998, p=0.040$; Fig. 2f). To further determine whether MyT1 overexpression affected spontaneous exploratory behavior, which may influence the performance on both EPM and OF tests, general locomotor activity was determined over the 15 -min test. The one-way ANOVA revealed that MyT1 overexpression had no effect

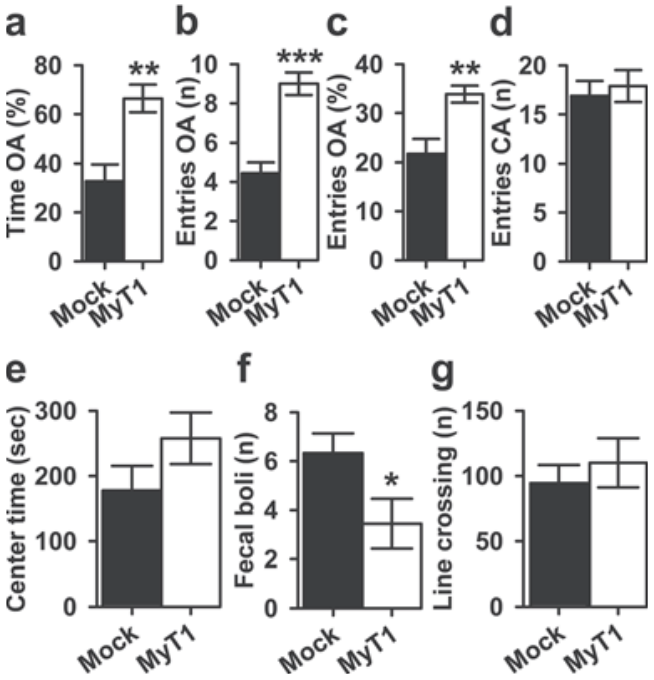

Fig. 2 Anxiety-like behavior in Mock- and MyT1-injected rats in the EPM and OF tests. The data are expressed as mean \pm SEM for a percentage of time spent on open arms $(O A), \mathbf{b}$ number, $\mathbf{c}$ percentage of entries into the on $\mathrm{OA}, \mathbf{d}$ number of entries into the closed arms $(C A)$ of the EPM, e time spent in the center of the arena, $\mathbf{f}$ number of fecal boli, and $\mathbf{g}$ number of line crossings in the OF test. $* p<0.05$, $* * p<0.005$, and $* * * p<0.0001$ indicate significant differences between Mock- and MyT1-injected rats. For each group, $n=9$

on the number of line crossings $\left(F_{(1,16)}=0.445, p=0.514\right.$; Fig. 2g), suggesting that the potential anxiolytic effects of MyT1 observed in both tests were not confounded by changes or deficits in overall spontaneous motor activity.

\section{Voluntary alcohol intake}

Ethanol consumption For analysis of the effects of MyT1 overexpression on voluntary ethanol intake and preference, the two-bottle choice drinking procedure was used. Continuous home cage access to $5 \%$ ethanol or water resulted in stable ethanol consumption in all animals (main effect of time: $\left.F_{(4,64)}=3.498, p=0.080\right)$. Values for daily ethanol consumption in the two experimental groups expressed as gram per kilogram are depicted in Fig. 3a. The one-way ANOVA analysis of this data showed that MyT1 overexpression

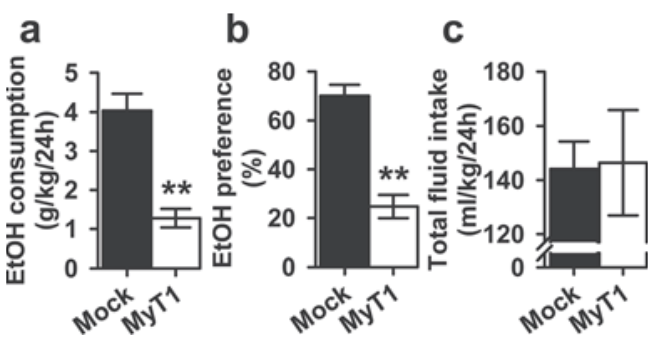

Fig. 3 Ethanol-related behaviors in Mock-and MyT1-injected rats in the two-bottle choice test. The data are expressed as mean \pm SEM for a ethanol consumption, $\mathbf{b}$ ethanol preference, and $\mathbf{c}$ total fluid intake. $* * p<0.0001$ indicates significant differences between Mock- and MyT1-injected rats. For each group, $n=9$ 
Fig. 4 Tastant intake related behaviors in Mock- and MyT1injected rats in the two-bottle choice test. The data are expressed as mean \pm SEM for $\mathbf{a}, \mathbf{d}$ saccharin and quinine consumption, b, e saccharin and quinine preference, and $\mathbf{c}, \mathbf{f}$ total fluid intake. $* p<0.001$ and $* * p<0.0001$ indicate significant differences between lower and higher concentrations. For each group, $n=9$ a

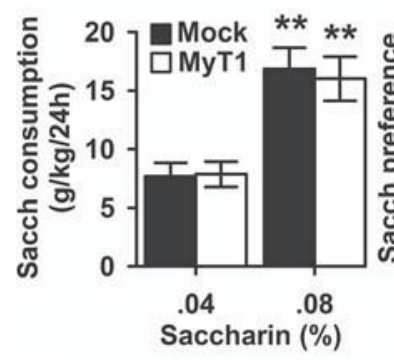

d

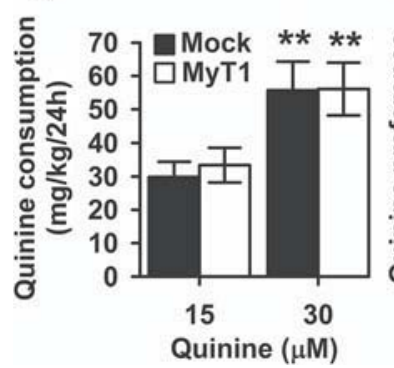

b

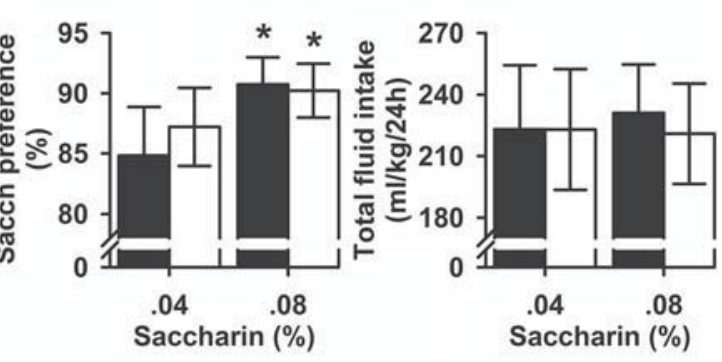

e

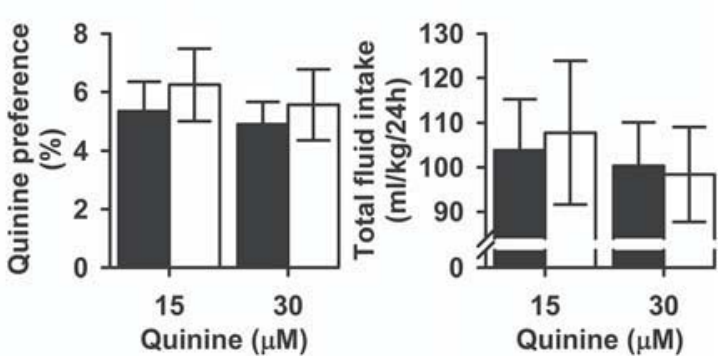

significantly decreased voluntary ethanol intake $\left(F_{(1}\right.$, 16) $=216.230, p<0.0001)$. Similarly, analysis of the alcohol preference data, expressed as a percentage of total fluid intake, showed that MyT1 overexpression reduced ethanol preference $\left(F_{(1,16)}=624.900, p<0.0001\right.$; Fig. 3b). Finally, the total fluid intake was measured and expressed as milliliters of fluid consumed per kilogram of body weight within $24 \mathrm{~h}$. This was averaged across the 5-day block. As shown in Fig. 3c, the one-way ANOVA showed that MyT1 overexpression had no effect on relative fluid consumption $\left(F_{(1,16)}=0.101, p=0.755\right)$, indicating that decreased ethanol consumption following MyT1 overexpression was not caused by an overall decrease in the total amount of fluid consumed.

\section{Tastant intake}

To determine whether differences in ethanol intake and preferences might reflect changes in taste preferences caused by MyT1 overexpression, drinking studies using a sweet appetitive rewarding substance (saccharin) or an aversive bitter solution (quinine) were performed and results are shown in Fig. 4.

Saccharin consumption The one-way ANOVA with repeated measures revealed that the two experimental groups escalated their saccharin intake when presented tastant in an unrestricted fashion as a choice against water in the two-bottle choice test $\left(F_{(1,34)}=18.206, p<0.001\right)$. However, there was no effect of MyT1 overexpression on voluntary saccharin intake $\left(F_{(1}\right.$, $\left.{ }_{34)}=0.218, p=0.644\right)$. Also, the concentration $\times \mathrm{MyT} 1$ interaction was not found significant $\left(F_{(1,34)}=0.464, p=0.500\right.$; Fig. 4a). Post hoc evaluations indicated that large increases in saccharin consumption were observed particularly when the higher concentration of saccharin $(0.08 \%)$ was presented.

Saccharin preference We then calculated the saccharin preference in the two experimental groups, and as expected, there was an increased preference for the highly concentrated saccharin solution $\left(F_{(1,34)}=15.930, p<0.001\right)$. However, no differences in the sweetener preference were found between Mock- and MyT1-injected rats $\left(F_{(1,34)}=0.122, p=0.729\right)$. Also, the concentration $\times$ MyT1 interaction was not found significant $\left(F_{(1,34)}=3.169, p=0.084\right.$; Fig. $\left.4 b\right)$.

Total fluid intake The one-way ANOVA with repeated measures indicated that neither concentration $\left(F_{(1,34)}=0.004\right.$, $p=0.949)$ nor MyT1 overexpression $\left(F_{(1,34)}=0.299\right.$, $p=0.588$ ) affected the total amount of fluid intake (saccharin + water). In addition, the interaction between the two factors $\left(F_{(1,34)}=0.197, p=0.660\right)$ was not found significant (Fig. 4c).

Quinine consumption Seven days after completion of the saccharin intake experiment, the same rats had access to quinine. In this test, rats could drink either tap water or an ascending series of quinine concentrations $(15$ and $30 \mu \mathrm{M})$. The one-way ANOVA with repeated measures revealed that quinine intake demonstrated significant dependence on concentration $\left(F_{(1,34)}=56.183, p<0.0001\right)$. However, no significant differences were found between the Mock- and Myt1-injected rats $\left(F_{(1,34)}=0.176, p=0.681\right)$. Also, the concentration $\times$ MyT1 interaction was not found significant $\left(F_{(1,34)}=0.244\right.$, $p=0.628$; Fig. 4d)). 
Quinine preference The one-way ANOVA with repeated measures revealed no significant effect of concentration $\left(F_{(1}\right.$, $34)=1.312, p=0.269)$ or MyT1 overexpression $\left(F_{(1,}\right.$ 34) $=1.277, p=0.275)$ on quinine preference. Also, the interaction between the two factors was not found significant $\left(F_{(1}\right.$, 34) $=0.067, p=0.799$; Fig. 4e).

Total fluid intake Finally and as displayed in Fig. 4f, the oneway ANOVA with repeated measures revealed that neither concentration $\left(F_{(1,34)}=1.437, p=0.248\right)$ nor MyT1 overexpression $\left(F_{(1,34)}=0.027, p=0.872\right)$ affected total fluid intake. Also, the concentration $\times$ MyT1 interaction was not found significant $\left(F_{(1,34)}=0.297, p=0.593 ;\right.$ Fig. $\left.4 f\right)$. Together, these results confirm that quinine concentrations used here were aversive to continuous-drinking rats, supporting the conclusion that MyT1 overexpression specifically reduced alcohol intake without altering taste palatability.

\section{MyT1 mRNA quantification and BEC}

Blood ethanol concentration In this experiment, we measured serum ethanol concentrations after alcohol injection in the two experimental groups. As shown in Table 1, the serum ethanol concentrations increased after alcohol injection and were at their maximum at $1 \mathrm{~h}$ after alcohol injection. The one-way ANOVA with repeated measures revealed that plasma ethanol concentrations decreased in a time-dependent manner $\left(F_{(2,32)}=95.726, p<0.0001\right)$. However, the ANOVA analysis confirmed that MyT1 overexpression was not effective in reducing plasma ethanol concentrations $\left(F_{(1}\right.$, 16) $=0.287, p=0.600)$. Also, the interaction between the two factors was not statistically significant $\left(F_{(2,32)}=0.385\right.$, $p=0.683$; Table 1).

mRNA quantification At the end of the behavioral experiments using viral vectors, the brains were removed, the DG subregion was dissected out, and MyT1 and BDNF mRNA levels were assessed using quantitative RT-PCR without and with transgene overexpression. The one-way ANOVA analysis revealed that the injection of the MyT1-expressing

Table 1 Blood ethanol concentrations in Mockand MyT1-injected rats

\begin{tabular}{lll}
\hline & Mock & MyT1 \\
\hline $1 \mathrm{~h}$ & $536.6 \pm 28.2$ & $575.5 \pm 72.0$ \\
$3 \mathrm{~h}$ & $411.9 \pm 25.7 *$ & $448.0 \pm 40.9$ \\
$6 \mathrm{~h}$ & $108.1 \pm 16.1 * *$ & $94.1 \pm 18.5 * *$ \\
\hline
\end{tabular}

The data are expressed as mean \pm SEM for blood alcohol concentrations 1,3 , and $6 \mathrm{~h}$ after an acute injection of $3 \mathrm{~g} / \mathrm{kg}$ ethanol. For each group, $n=9$

$* p=0.003, * * p<0.0001$, significant differences between 1 and $3 \mathrm{~h}$ and between 1 and $6 \mathrm{~h}$, respectively

lentiviral vectors resulted in a marked upregulation of mRNA expression levels for both MyT1 and BDNF genes $\left(F_{(1,16)}=26.843, p<0.0001\right.$ and $F_{(1,16)}=25.627$, $p<0.0001$, respectively; Table 2).

Using the mRNA levels obtained from the Mock- and MyT1-injected rats, a simple linear regression (Pearson's) analysis was performed to examine the correlation between either MyT1 or BDNF transcription levels and parameters of anxiety and ethanol consumption and preference. Results are depicted in Figs. 5 and 6. The correlation coefficient $(r)$ for the difference between the MyT1 mRNA amount and the percent of time spent into the OA of the EPM was 0.542 and the two parameters correlated significantly ( $p=0.020$; Fig. 5a). Also, there was a significant positive correlation between MyT1 mRNA expression with the number of entries into the OA (Pearson's test: $r=0.679, p=0.002$; Fig. 5b), and with the percentage of entries into the OA (Pearson's test: $r=0.564$, $p=0.015$; Fig. $5 \mathrm{c}$ ), but not with the number of entries into the CA $(r=0.069, p=0.785$; Fig. $5 d)$. In the OF test, the Pearson's analysis revealed that neither the time spent in the center of the arena ( $r=0.393, p=0.107$; Fig. 5e) nor the number of line crossings $(r=0.334, p=0.176$; data not shown) were correlated with MyT1 mRNA levels. However, there was a significant negative correlation between MyT1 mRNA and the number of fecal boli left in the arena ( $r=-0.579, p=0.012$; Fig. 5f). The relations between MyT1 mRNA levels and ethanol consumption were also determined by Pearson's correlation analysis, and we found a significant negative correlation between MyT1 mRNA levels with voluntary alcohol intake $(r=-0.735, p=0.001$; Fig. $5 \mathrm{~g})$ and with ethanol preference $(r=-0.796, p<0.001$; Fig. 5h) but not with total fluid intake ( $r=0.258, p=0.301$; Fig. 5i). Finally, and most impressively, the Pearson's analysis showed a significant positive correlation between MyT1 and BDNF mRNA levels (Pearson's test: $r=0.509, p=0.031$; Fig. 5j).

Pearson correlation analysis between BDNF mRNA values and measures of anxiety- and ethanol-related behaviors were also calculated. Results demonstrated statistically significant positive correlation between BDNF mRNA with the percentage of time spent into the OA (Pearson's test: $r=0.568$, $p=0.014$; Fig. 6a), with the number $(r=0.659, p=0.003$; Fig. $6 \mathrm{~b})$ and the percentage of entries into the OA $(r=0.572$,

Table 2 mRNA levels in Mock and MyT1 rats as measured by RT-PCR

\begin{tabular}{lll}
\hline & Mock & MyT1 \\
\hline MyT1 & $1.12 \pm 0.21$ & $3.19 \pm 0.34^{*}$ \\
BDNF & $1.16 \pm 0.15$ & $2.83 \pm 0.29 *$ \\
\hline
\end{tabular}

The data are expressed as mean \pm SEM for MyT1 and BDNF mRNA levels. For each group, $n=9$

$* p<0.0001$, significant differences between Mock- and MyT1-injected rats 

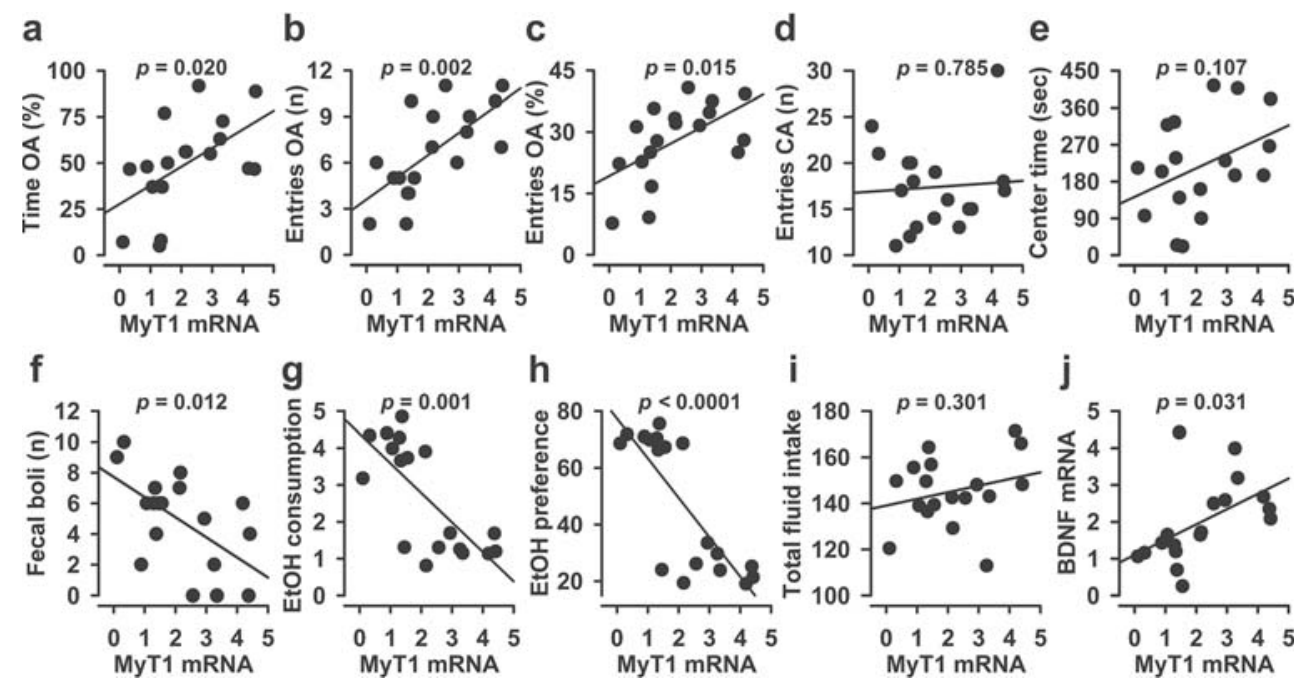

Fig. 5 Person correlations. The data represent simple scatter regression between MyT1 mRNA levels with a percentage of time into the OA, b number of entries into the OA, c percentage of entries into the OA, d

$p=0.013$; Fig. $6 \mathrm{c})$, but not with the number of entries into the CA $(r=0.018, p=0.942$; Fig. $6 d)$. Additionally, there was no correlation between BDNF mRNA values with the time spent in the center of the arena $(r=0.341, p=0.166$; Fig. $6 \mathrm{e})$, with the number of fecal boli ( $r=-0.423, p=0.080$; Fig. $6 \mathrm{f})$, or with the number of line crossings $(r=0.197, p=0.433$; data not shown) of the OF test. Correlation of BDNF mRNA values with ethanol consumption was computed and is depicted in Fig. 6g. BDNF mRNA was significantly negatively correlated with ethanol consumption ( $r=-0.746, p<0.0001$; Fig. $6 \mathrm{~g}$ ) and ethanol preference $(r=-0.751, p<0.0001$; Fig. $6 \mathrm{~h})$ but not with total fluid intake $(r=-0.009, p=0.971$; data not shown).

These findings suggest that rats with high MyT1 mRNA expression levels in the DG are most likely to have high number of entries into the CA of the EPM, e time spent in the center of the arena, $\mathbf{f}$ number of fecal boli of the OF, $\mathbf{g}$ ethanol consumption, $\mathbf{h}$ ethanol preference, $\mathbf{i}$ total fluid intake, and $\mathbf{j}$ BDNF mRNA levels

BDNF mRNA levels inducing reduced anxiety-like phenotypes that are in turn associated with lower ethanol consumption and preference.

\section{Discussion}

The results of the current study expand previous reports that genetic manipulations, using viral vectors, believed to alter central MyT1 expression and hippocampal BDNF signaling may be effective in attenuating anxiety-like behavior and diminishing voluntary ethanol intake and preference. We report that anxiety-like behavior on the EPM and OF tests was decreased following lentiviral-mediated overexpression of MyT1 in the DG of the hippocampus, relative to control
Fig. 6 Person correlations. The data represent simple scatter regression between $\mathrm{BDNF}$ mRNA levels with a percentage of time into the OA, $\mathbf{b}$ number of entries into the $\mathrm{OA}, \mathbf{c}$ percentage of entries into the OA, $\mathbf{d}$ number of entries into the CA of the EPM, e time spent in the center of the arena, $\mathbf{f}$ number of fecal boli of the $\mathrm{OF}, \mathbf{g}$ ethanol consumption, and $\mathbf{h}$ ethanol preference
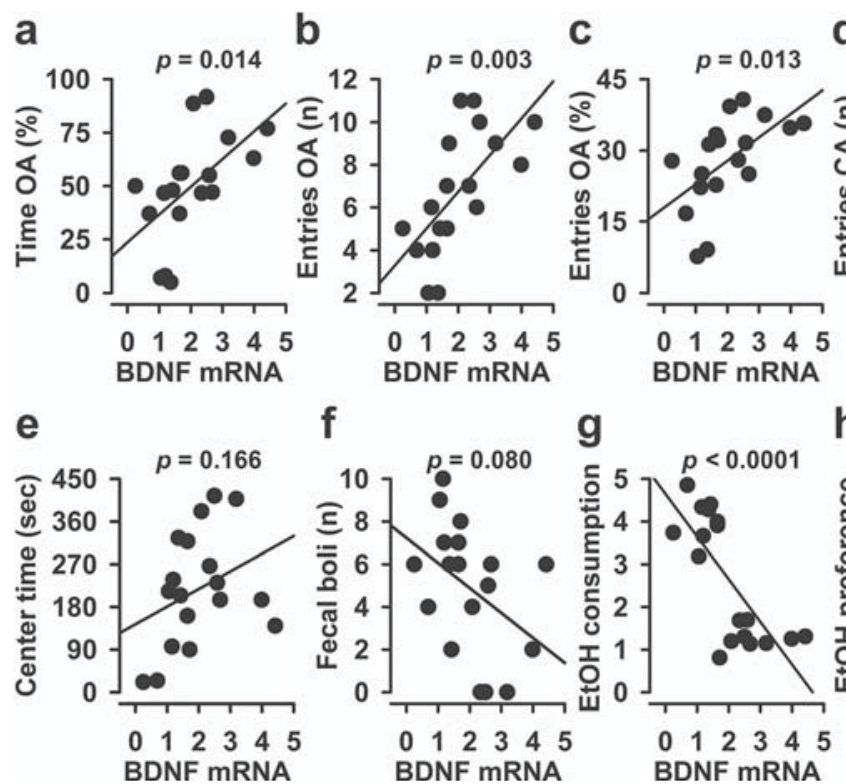

f

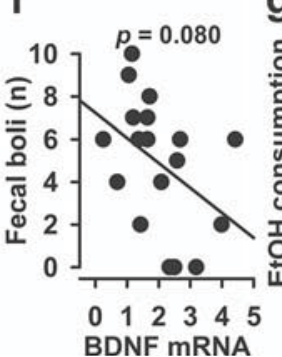

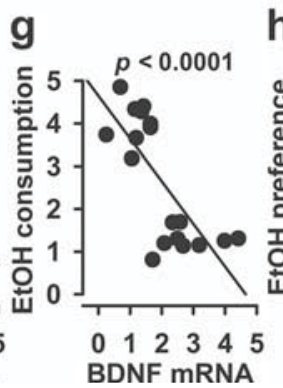

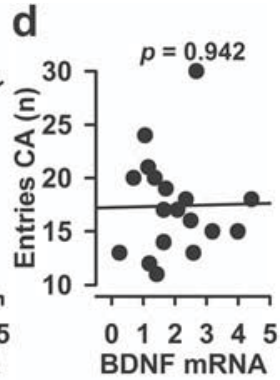

h

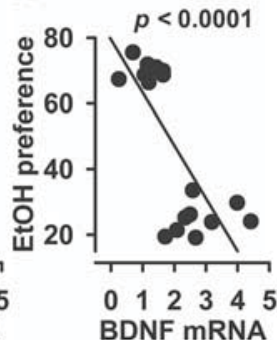


animals. Interestingly, MyT1 overexpression decreased voluntary ethanol intake and preference but had no effect on saccharin and quinine intake, used to assess taste discrimination, and similar BECs. Importantly, MyT1 overexpression was associated with increased mRNA levels of both MyT1 and BDNF in the DG. Finally, increased MyT1 and BDNF mRNA levels in the DG were correlated with decreased anxiety-like behavior and ethanol consumption and preference.

To our knowledge, this is the first study to directly seek an association between the ability of ectopically overexpressed MyT1 to reduce anxiety-like behaviors and ethanol intake in the same animals. Our results confirm that using viral vectors aimed at increasing MyT1 expression in discrete and specific brain region (such as the DG) reduces both the expression of anxiety-like behavior and ethanol intake in well-validated rodent models. The observed effectiveness of MyT1-expressing lentiviral vectors in reducing ethanol drinking while apparently inducing anxiolysis is very encouraging, as these findings correspond with their efficacy in attenuating both cocaineinduced locomotor stimulation (Chandrasekar and Dreyer 2010a) and cocaine self-administration (Chandrasekar and Dreyer 2010b) in rats.

It is interesting to emphasize that MyT1-decreased anxietylike behavior affected all the parameters of the EPM test. However, in the OF test, MyT1 overexpression only reduced the number of fecal boli but had no effect on the time spent in the center of the arena. Nevertheless, this finding is not surprising because it has been suggested that the time spent in the center of the arena of the OF test may not be the most appropriate assay for measuring the efficacy of all anxiolytic compounds. As a matter of fact, Prut and Belzung reported in their review that compounds such as adinazolam, alprazolam, and selective serotonin reuptake inhibitors that have a different spectrum of therapeutic efficacy in anxiety disorders were poorly effective as anxiolytics in the OF test (Prut and Belzung 2003). The same discrepancies were also observed by Fejemiroye et al. who reported that oleanolic acid demonstrated an anxiolytic effect in both the light-dark box and EPM tests but not in the OF test (Fajemiroye et al. 2014) suggesting that this paradigm may not perfectly model the characteristics of anxiety disorders. Regardless, lower fecal boli count during the OF test was associated to decreased anxiety-like phenotype in several studies (Amorim et al. 2014; Fulk et al. 2004; Hill and Gorzalka 2006; Lund et al. 2005). To our knowledge, our findings are the first to confirm that reduced ethanol drinking resulting from MyT1 overexpression - that putatively increased hippocampal BDNF signaling - is accompanied by significantly diminished anxietylike behavior.

Although we did not directly assess the underlying neurobiological mechanisms by which MyT1 overexpression in the DG reduced anxiety and ethanol consumption, we can speculate as to how they are affecting these behaviors. In fact, evidence from the current study suggested that BDNF mRNA expression was positively correlated with MyT1 mRNA expression. Interestingly, prior research in our lab has revealed that in the nucleus accumbens (NAcc), MyT1 expression resulted in downregulation of BDNF expression (Chandrasekar and Dreyer 2010b). As such, it will be important in future studies to examine the discrepancies in BDNF mRNA expression in the NAcc and the DG upon MyT1 overexpression. Nevertheless, previous studies have shown that central BDNF signaling affects both anxiety and ethanol self-administration. Our results are in agreement with initial data demonstrating that transgenic mice overexpressing the full-length BDNF receptor TrkB reduced anxiety in the EPM and lightdark exploration tests (Koponen et al. 2004). Also, peripheral BDNF administration increased time spent in the open arms of an EPM (Schmidt and Duman 2010) which is also on line with increased anxiety in mice with a BDNF mutation that decreases secretion (Chen et al. 2006). Furthermore, mice subjected to a battery of stressors for 28 days showed partial anxiety-like behavior in the EPM and the OF tests with a significant low serum BDNF levels (Mahesh and Bhatt 2013). Similarly, the adult male offspring, of dams phenotyped as high-anxiety, exhibited less anxiety traits in the EPM test than their maternal line and showed markedly more BDNF immunoreacted cells in the amygdala, the CA1 and CA2 hippocampal regions, and the caudate putamen (Berman et al. 2014). Clinical investigations have demonstrated that reduced BDNF levels have also been implicated in the etiology of stress-related psychiatric disorders such as anxiety (Shang et al. 2015). And consistent with these findings, Lee et al. found that single prolonged stress decreases the expression of BDNF mRNA in the rat hippocampus, decreasing anxiety-like behaviors (Lee et al. 2016). However, the role of high levels of hippocampal BDNF is unclear as some reports suggested anxiogenic-like effects. In fact, it should be emphasized that our results are not in agreement with previous studies showing that transgenic overexpression of BDNF had an unexpected facilitatory effect on anxiety-like behavior (Govindarajan et al. 2006) and that intrahippocampal injection of BDNF induced an anxiogenic-like activity in both the OF and EPM paradigms (Deltheil et al. 2009). Differences between these results could be due, at least in part, to procedural differences and to a species-dependent effect of BDNF (rats vs. mice). Nevertheless, these findings suggest that low levels for anxiety traits correlate with high BDNF expression levels.

Interestingly, high BDNF mRNA levels were also associated to lower ethanol intake and preference and did not appear to affect total fluid intake. This is not surprising, as there is evidence from our laboratory that lentiviral-mediated overexpression of BDNF in the dorsolateral striatum significantly attenuated ethanol-induced place preference as well as voluntary alcohol consumption (Bahi and Dreyer 2013). Our results 
are in agreement with those reported by others showing that ethanol intake increases BDNF mRNA expression in the dorsal striatum (Jeanblanc et al. 2009) and heterozygous BDNF mice displayed increased ethanol intake in a two-bottle choice procedure (Hensler et al. 2003), greater preference for the environment paired with ethanol injection than that observed in wild-type control mice, and enhanced ethanol-induced locomotor sensitization (McGough et al. 2004). Furthermore, it was found that inhibition of the BDNF receptor TrkB increases voluntary ethanol consumption in wild-type mice (Jeanblanc et al. 2006), while downregulation of endogenous BDNF using viral-mediated siRNA in the dorsolateral striatum significantly increased ethanol self-administration, and that infusion of exogenous BDNF $(0.25 \mu \mathrm{g} / \mu \mathrm{L})$ attenuated responding for ethanol when infused $3 \mathrm{~h}$ before the beginning of the self-administration session (Jeanblanc et al. 2009). In the brain of alcohol-preferring AA rats, the level of BDNF mRNA expression was higher in the amygdala and ventral tegmental area than in those of alcohol-avoiding ANA rats, and there was a trend for a higher level in the NAcc (Raivio et al. 2014). It should be emphasized that studies from Heilig and Ron's laboratories proposed a different mechanism of BDNF regulation. In fact, they have shown that viralmediated overexpression of microRNA-206 in the medial prefrontal cortex significantly inhibited BDNF expression and induced an escalation of alcohol self-administration (Tapocik et al. 2014). Similarly, overexpression of microRNA-30a-5p in the same brain region produced an escalation of alcohol intake and a preference over water that was associated to decreased BDNF expression (Darcq et al. 2015). Several studies have examined how BDNF might affect the interaction between anxiety and alcohol intake. For instance, BDNF antisense oligodeoxynucleotide infusions into the central amygdala and medial amygdala but not basolateral amygdala provoked increased voluntary ethanol intake and anxiety-like behaviors in rats. Interestingly, the levels of BDNF, phosphorylated extracellular signal-regulated kinases 1/2 (p-ERK1/2), and phosphorylated cAMP responsive-element binding protein ( $\mathrm{p}$-CREB) were decreased by BDNF antisense, but both the effects on protein phosphorylation and behavior were reversed when BDNF was co-infused with the antisense oligonucleotides (Pandey et al. 2006). The same group also identified a subsequent step in the signaling pathway induced by BDNF involving the activity-regulated cytoskeleton-associated protein (Arc). Morphologically, these behavioral changes were associated to significant alterations in dendritic spine density in the amygdala (Pandey et al. 2008). Taken together, these findings suggest that the innate levels of BDNF expression as well as CREB/Arc signaling may play a role in the molecular processes of the comorbidity between anxiety and alcohol-drinking behaviors. Our results indicate that MyT1 overexpression in the dentate gyrus induced an increase of BDNF expression that significantly decreases ethanol self- administration and that this decrease in drinking is accompanied by marked reductions in the expression of anxiety-like behavior. Specifically, we propose that hippocampal endogenous BDNF activation, through MyT1, controls the level of anxiety and consequently levels of ethanol self-administration by reducing the reinforcing effects of ethanol. Therefore, activation of the hippocampal BDNF pathway may prove efficacious in the treatment of anxiety disorders and alcoholism.

Acknowledgements The authors would like to acknowledge Mrs. Christine Deforel-Poncet and Dr. Vijay Chandrasekar for their technical assistance with the lentiviral vector preparation. The authors are also grateful to Mr. Mohamed Shafiullah and Dr. Mahmoud Hag Ali from the Central Animal Facility for their advice on animal care and welfare.

Role of the funding source $\mathrm{AB}$ was supported by grants from the United Arab Emirates University (No. NP/13/05) and the National Research foundation (No. 31M082). JLD received grants from the Swiss National Science Foundation 3100-059350 and 3100AO-100686 (JLD). The funders had no further role in study design; in the collection, analysis, and interpretation of data; in the writing of the report; and in the decision to submit the paper for publication.

\section{Compliance with ethical standards}

Conflict of interest The authors have no financial interests that might be perceived to influence the results or the discussion reported in this article.

\section{References}

Amorim D, David-Pereira A, Pertovaara A, Almeida A, Pinto-Ribeiro F (2014) Amitriptyline reverses hyperalgesia and improves associated mood-like disorders in a model of experimental monoarthritis. Behav Brain Res 265:12-21

Anderson ML, Nokia MS, Govindaraju KP, Shors TJ (2012) Moderate drinking? Alcohol consumption significantly decreases neurogenesis in the adult hippocampus. Neuroscience 224:202-209

Aubrecht TG, Weil ZM, Nelson RJ (2014) Melatonin treatment during early life interacts with restraint to alter neuronal morphology and provoke depressive-like responses. Behav Brain Res 263:90-97

Bahi A (2013) Viral-mediated knockdown of mGluR7 in the nucleus accumbens mediates excessive alcohol drinking and increased ethanol-elicited conditioned place preference in rats. Neuropsychopharmacology 38:2109-2119

Bahi A (2016) Sustained lentiviral-mediated overexpression of microRNA124a in the dentate gyrus exacerbates anxiety- and autism-like behaviors associated with neonatal isolation in rats. Behav Brain Res 311:298-308

Bahi A, Dreyer JL (2013) Striatal modulation of BDNF expression using microRNA124a-expressing lentiviral vectors impairs ethanolinduced conditioned-place preference and voluntary alcohol consumption. Eur J Neurosci 38:2328-2337

Bahi A, Boyer F, Chandrasekar V, Dreyer JL (2008) Role of accumbens BDNF and TrkB in cocaine-induced psychomotor sensitization, conditioned-place preference, and reinstatement in rats. Psychopharmacology 199:169-182

Bahi A, Al Mansouri S, Al Maamari E (2016) Nucleus accumbens lentiviral-mediated gain of function of the oxytocin receptor regulates anxiety- and ethanol-related behaviors in adult mice. Physiol Behav 164:249-258 
Berman AK, Lott RB, Donaldson ST (2014) Periodic maternal deprivation may modulate offspring anxiety-like behavior through mechanisms involving neuroplasticity in the amygdala. Brain Res Bull 101:7-11

Chandrasekar V, Dreyer JL (2010a) The brain-specific neural zinc finger transcription factor $2 \mathrm{~b}$ (NZF-2b/7ZFMyt1) causes suppression of cocaine-induced locomotor activity. Neurobiol Dis 37:86-98

Chandrasekar V, Dreyer JL (2010b) The brain-specific neural zinc finger transcription factor $2 \mathrm{~b}$ (NZF-2b/7ZFMyt1) suppresses cocaine selfadministration in rats. Front Behav Neurosci 4:14

Chen ZY, Jing D, Bath KG, Ieraci A, Khan T, Siao CJ, Herrera DG, Toth M, Yang C, McEwen BS, Hempstead BL, Lee FS (2006) Genetic variant BDNF (Val66Met) polymorphism alters anxiety-related behavior. Science 314:140-143

Czeh B, Michaelis T, Watanabe T, Frahm J, de Biurrun G, van Kampen M, Bartolomucci A, Fuchs E (2001) Stress-induced changes in cerebral metabolites, hippocampal volume, and cell proliferation are prevented by antidepressant treatment with tianeptine. Proc Natl Acad Sci U S A 98:12796-12801

Darcq E, Warnault V, Phamluong K, Besserer GM, Liu F, Ron D (2015) MicroRNA-30a-5p in the prefrontal cortex controls the transition from moderate to excessive alcohol consumption. Mol Psychiatry 20:1219-1231

Deltheil T, Tanaka K, Reperant C, Hen R, David DJ, Gardier AM (2009) Synergistic neurochemical and behavioural effects of acute intrahippocampal injection of brain-derived neurotrophic factor and antidepressants in adult mice. Int $\mathrm{J}$ Neuropsychopharmacol 12:905-915

Earnheart JC, Schweizer C, Crestani F, Iwasato T, Itohara S, Mohler H, Luscher B (2007) GABAergic control of adult hippocampal neurogenesis in relation to behavior indicative of trait anxiety and depression states. J Neurosci 27:3845-3854

Eom KS, Cheong JS, Lee SJ (2016) Structural analyses of zinc finger domains for specific interactions with DNA. J Microbiol Biotechnol 26:2019-2029

Fajemiroye JO, Galdino PM, Florentino IF, Da Rocha FF, Ghedini PC, Polepally PR, Zjawiony JK, Costa EA (2014) Plurality of anxiety and depression alteration mechanism by oleanolic acid. J Psychopharmacol 28:923-934

Fernandez-Enright F, Andrews JL, Newell KA, Pantelis C, Huang XF (2014) Novel implications of lingo-1 and its signaling partners in schizophrenia. Transl Psychiatry 4:e348

Fulk LJ, Stock HS, Lynn A, Marshall J, Wilson MA, Hand GA (2004) Chronic physical exercise reduces anxiety-like behavior in rats. Int J Sports Med 25:78-82

Gamsjaeger R, O'Connell MR, Cubeddu L, Shepherd NE, Lowry JA, Kwan AH, Vandevenne M, Swanton MK, Matthews JM, Mackay JP (2013) A structural analysis of DNA binding by myelin transcription factor 1 double zinc fingers. J Biol Chem 288:35180-35191

Ghisleni G, Kazlauckas V, Both FL, Pagnussat N, Mioranzza S, Rocha JB, Souza DO, Porciuncula LO (2008) Diphenyl diselenide exerts anxiolytic-like effect in Wistar rats: putative roles of GABAA and 5HT receptors. Prog Neuro-Psychopharmacol Biol Psychiatry 32: $1508-1515$

Gould E, Tanapat P, Rydel T, Hastings N (2000) Regulation of hippocampal neurogenesis in adulthood. Biol Psychiatry 48:715-720

Govindarajan A, Rao BS, Nair D, Trinh M, Mawjee N, Tonegawa S, Chattarji S (2006) Transgenic brain-derived neurotrophic factor expression causes both anxiogenic and antidepressant effects. Proc Natl Acad Sci U S A 103:13208-13213

Grant BF, Stinson FS, Dawson DA, Chou SP, Dufour MC, Compton W, Pickering RP, Kaplan K (2004) Prevalence and co-occurrence of substance use disorders and independent mood and anxiety disorders: results from the National Epidemiologic Survey on Alcohol and Related Conditions. Arch Gen Psychiatry 61:807-816
Hensler JG, Ladenheim EE, Lyons WE (2003) Ethanol consumption and serotonin-1A (5-HT1A) receptor function in heterozygous BDNF (+/-) mice. J Neurochem 85:1139-1147

Hill MN, Gorzalka BB (2006) Increased sensitivity to restraint stress and novelty-induced emotionality following long-term, high dose cannabinoid exposure. Psychoneuroendocrinology 31:526-536

Jeanblanc J, He DY, McGough NN, Logrip ML, Phamluong K, Janak $\mathrm{PH}$, Ron D (2006) The dopamine D3 receptor is part of a homeostatic pathway regulating ethanol consumption. J Neurosci 26: 1457-1464

Jeanblanc J, He DY, Carnicella S, Kharazia V, Janak PH, Ron D (2009) Endogenous BDNF in the dorsolateral striatum gates alcohol drinking. J Neurosci 29:13494-13502

Jiang Y, Yu VC, Buchholz F, O'Connell S, Rhodes SJ, Candeloro C, Xia YR, Lusis AJ, Rosenfeld MG (1996) A novel family of Cys-Cys, His-Cys zinc finger transcription factors expressed in developing nervous system and pituitary gland. J Biol Chem 271:10723-10730

Jindal A, Mahesh R, Bhatt S (2013) Etazolate rescues behavioral deficits in chronic unpredictable mild stress model: modulation of hypothalamic-pituitary-adrenal axis activity and brain-derived neurotrophic factor level. Neurochem Int 63:465-475

Kampman KM, Pettinati H, Volpicelli J, Kaempf G, Turk E, Insua A, Lipkin C, Sparkman T, O’Brien CP (2002) Concurrent cocaine withdrawal alters alcohol withdrawal symptoms. J Addict Dis 21:13-26

Karpyak VM, Biernacka JM, Geske JR, Abulseoud OA, Brunner MD, Chauhan M, Hall-Flavin DK, Lewis KA, Loukianova LL, Melnyk GJ, Onsrud DA, Proctor BD, Schneekloth TD, Skime MK, Wittkopp JE, Frye MA, Mrazek DA (2016) Gender-specific effects of comorbid depression and anxiety on the propensity to drink in negative emotional states. Addiction 111:1366-1375

Kendler KS, Davis CG, Kessler RC (1997) The familial aggregation of common psychiatric and substance use disorders in the National Comorbidity Survey: a family history study. Br J Psychiatry 170: $541-548$

Kitahara Y, Ohta K, Hasuo H, Shuto T, Kuroiwa M, Sotogaku N, Togo A, Nakamura K, Nishi A (2016) Chronic fluoxetine induces the enlargement of perforant path-granule cell synapses in the mouse dentate gyrus. PLoS One 11:e147307

Koponen E, Voikar V, Riekki R, Saarelainen T, Rauramaa T, Rauvala H, Taira T, Castren E (2004) Transgenic mice overexpressing the fulllength neurotrophin receptor trkB exhibit increased activation of the trkB-PLCgamma pathway, reduced anxiety, and facilitated learning. Mol Cell Neurosci 26:166-181

Lacaille H, Duterte-Boucher D, Liot D, Vaudry H, Naassila M, Vaudry D (2015) Comparison of the deleterious effects of binge drinking-like alcohol exposure in adolescent and adult mice. J Neurochem 132: 629-641

Laity JH, Lee BM, Wright PE (2001) Zinc finger proteins: new insights into structural and functional diversity. Curr Opin Struct Biol 11:39 46

Leal-Galicia P, Saldivar-Gonzalez A, Morimoto S, Arias C (2007) Exposure to environmental enrichment elicits differential hippocampal cell proliferation: role of individual responsiveness to anxiety. Dev Neurobiol 67:395-405

Lee B, Sur B, Yeom M, Shim I, Lee H, Hahm DH (2016) Effects of systemic administration of ibuprofen on stress response in a rat model of post-traumatic stress disorder. Korean J Physiol Pharmacol 20:357-366

Li W, Wang X, Zhao J, Lin J, Song XQ, Yang Y, Jiang C, Xiao B, Yang G, Zhang HX, Lv LX (2012) Association study of myelin transcription factor 1-like polymorphisms with schizophrenia in Han Chinese population. Genes Brain Behav 11:87-93

Lund TD, Rovis T, Chung WC, Handa RJ (2005) Novel actions of estrogen receptor-beta on anxiety-related behaviors. Endocrinology 146: 797-807 
Malberg JE, Eisch AJ, Nestler EJ, Duman RS (2000) Chronic antidepressant treatment increases neurogenesis in adult rat hippocampus. J Neurosci 20:9104-9110

Matthews JM, Sunde M (2002) Zinc fingers-folds for many occasions. IUBMB Life 54:351-355

McGough NN, He DY, Logrip ML, Jeanblanc J, Phamluong K, Luong K, Kharazia V, Janak PH, Ron D (2004) RACK1 and brain-derived neurotrophic factor: a homeostatic pathway that regulates alcohol addiction. J Neurosci 24:10542-10552

Nielsen JA, Hudson LD, Armstrong RC (2002) Nuclear organization in differentiating oligodendrocytes. J Cell Sci 115:4071-4079

Nielsen JA, Berndt JA, Hudson LD, Armstrong RC (2004) Myelin transcription factor 1 (Myt1) modulates the proliferation and differentiation of oligodendrocyte lineage cells. Mol Cell Neurosci 25:111123

Pandey SC, Zhang H, Roy A, Misra K (2006) Central and medial amygdaloid brain-derived neurotrophic factor signaling plays a critical role in alcohol-drinking and anxiety-like behaviors. J Neurosci 26: $8320-8331$

Pandey SC, Zhang H, Ugale R, Prakash A, Xu T, Misra K (2008) Effector immediate-early gene arc in the amygdala plays a critical role in alcoholism. J Neurosci 28:2589-2600

Paxinos G, Watson C (1998) The rat brain in stereotaxic coordinates. San Diego Academic Press

Prut L, Belzung C (2003) The open field as a paradigm to measure the effects of drugs on anxiety-like behaviors: a review. Eur J Pharmacol 463:3-33
Raivio N, Miettinen P, Kiianmaa K (2014) Innate BDNF expression is associated with ethanol intake in alcohol-preferring AA and alcoholavoiding ANA rats. Brain Res 1579:74-83

Schmidt HD, Duman RS (2010) Peripheral BDNF produces antidepressant-like effects in cellular and behavioral models. Neuropsychopharmacology 35:2378-2391

Shang L, Xu TL, Li F, Su J, Li WG (2015) Temporal dynamics of anxiety phenotypes in a dental pulp injury model. Mol Pain 11:40

Tapocik JD, Barbier E, Flanigan M, Solomon M, Pincus A, Pilling A, Sun H, Schank JR, King C, Heilig M (2014) microRNA-206 in rat medial prefrontal cortex regulates BDNF expression and alcohol drinking. J Neurosci 34:4581-4588

Trejo JL, Llorens-Martin MV, Torres-Aleman I (2008) The effects of exercise on spatial learning and anxiety-like behavior are mediated by an IGF-I-dependent mechanism related to hippocampal neurogenesis. Mol Cell Neurosci 37:402-411

Wang T, Zeng Z, Li T, Liu J, Li J, Li Y, Zhao Q, Wei Z, Wang Y, Li B, Feng G, He L, Shi Y (2010) Common SNPs in myelin transcription factor 1-like (MYT1L): association with major depressive disorder in the Chinese Han population. PLoS One 5:e13662

Wang B, Zheng Y, Shi H, Du X, Zhang Y, Wei B, Luo M, Wang H, Wu X, Hua X, Sun M, Xu X (2016) Zfp462 deficiency causes anxiety-like behaviors with excessive self-grooming in mice. Genes Brain Behav 16:296-307 